\title{
EL PRINCIPAL IMPULSOR DE LA RESPONSABILIDAD SOCIAL EMPRESARIAL EN LAS PYMES
}

Adriana Laura Cruz y Corro Sánchez

Doctora en Administración

Coordinadora del Posgrado en Ingeniería Financiera, departamento de Negocios, Universidad Iberoamericana de Puebla, México adriana.cruzycorro.sanchez@iberopuebla.mx

En México, las pequeñas y medianas empresas (pymes) son fundamentales en su economía; según cifras actualizadas al 2020, el Instituto Nacional de Estadística y Geografía (INEGI) estima que de los 4.9 millones de micro, pequeños y medianos establecimientos sobreviven 3.9 millones, que representan el $79.19 \%$, mientras que $1,010,857$ de establecimientos (20.81\%) cerraron sus puertas definitivamente. Por otro lado, el mismo estudio muestra que nacieron 619,443 establecimientos que representan $12.75 \%$ de la población de negocios del país.

En términos económicos, estas empresas generan más del $70 \%$ de empleos formales y aportan el $52 \%$ al Producto Interno Bruto, además siguen representando un eslabón fundamental en la cadena productiva. En contraste con lo anterior, varios estudios demuestran que tratándose de Responsabilidad Social Empresarial (RSE) no hay un desempeño profundo en el tema, a tal grado, que muchas pymes no logran identificarla, confundiéndola con filantropía.

Sin embargo, Jamali, Zanhour y Keshishian (2009) afirman que este tipo de empresas realizan acciones responsables que forman parte del fenómeno denominado "responsabilidad social silenciosa". Esto significa que llevan a cabo Prácticas de Responsabilidad Social (PRS), pero no las identifican como tal; estas prácticas son motivadas por varios factores, entre ellos la cercanía que tienen con ciertos grupos de interés como sus colaboradores, clientes y proveedores.

En el marco de los planteamientos anteriores, se realizó un estudio sobre las PRS que realizan las pymes poblanas restauranteras donde el propósito fue reconocer aquellos factores que motivan $y$ ejercen presión para que estas empresas asuman comportamientos responsables, factores que en la literatura también son llamados impulsores. En este sentido, existen estudios como los realizados por Villavicencio, Sánchez, Fornachiari (2015) que concluyen que son cinco los factores que inciden en el desarrollo de la PRS: a) Los consumidores, porque tienen capacidad adquisitiva para satisfacer sus necesidades a través del mercado y son cada día más exigentes no sólo con el producto, sino con los valores de la empresa y su cumplimiento con las leyes.

b) Los proveedores ya que al implementar PRS como estrategia de RSE los ayuda a posicionarse en un mercado competitivo.

c) La comunidad ya que otorgan el derecho de uso a la empresa para situarse en su zona.

d) El medio ambiente porque la empresa debe asumir su responsabilidad en el uso de recursos no renovables y las consecuencias que representen su actividad en él.

e) La competitividad porque estimula acciones responsables derivadas del análisis de sus impactos en su gestión empresarial.

Se debe agregar que hay otros impulsores como leyes ambientales y laborales eficientes, mercados financieros que exijan responsabilidades antes y después de invertir o prestar, la imagen y reputación de la empresa, etc. Para todo lo anterior es fundamental, afirma Vives (2008), la formación de profesionales comprometidos y empresas presionadas por el mercado y la competencia a sostener sus prácticas de RSE, todo esto bajo la mirada de una sociedad civil activa que presione a los sectores públicos y privados.

Para llevar a cabo el análisis de los impulsores de las PRS en las pymes antes referidas la tabla 1 muestra los principales hallazgos de una serie de estudios que identificaron y analizaron los principales impulsores de las PRS en diferentes países del mundo. La tabla muestra los impulsores que con más frecuencia aparecieron en los seis estudios revisados en España, Latinoamérica y a nivel mundial. 


\section{Tabla 1}

Impulsores Identificados en 6 estudios sobre RSE

\begin{tabular}{|c|c|c|}
\hline España & Latinamérica & Mundial \\
\hline $\begin{array}{c}\text { Valores personales y creencias } \\
\text { éticas }\end{array}$ & $\begin{array}{c}\text { Razones éticas y/o religiosas, } \\
\text { Valores }\end{array}$ & $\begin{array}{c}\text { Creencias éticas y valores del } \\
\text { propietario / gerente }\end{array}$ \\
\hline $\begin{array}{l}\text { Consumidor con preferencias } \\
\text { sociales y medioambientales }\end{array}$ & Consumidores educados & \\
\hline Proveedores & $\begin{array}{l}\text { Mejorar la lealtad de } \\
\text { proveedores }\end{array}$ & $\begin{array}{c}\text { Presiones de la cadena de } \\
\text { suministro }\end{array}$ \\
\hline $\begin{array}{l}\text { Mayor contribución con } \\
\text { comunidad }\end{array}$ & $\begin{array}{l}\text { Mejorar las relaciones con la } \\
\text { comunidad / autoridades }\end{array}$ & Creación de capital social \\
\hline Mejorar la competividad & $\begin{array}{c}\text { Exposición a la competencia y } \\
\text { globalización }\end{array}$ & \\
\hline \multirow[t]{2}{*}{$\begin{array}{l}\text { Cumplir con la legislación } \\
\text { imagen y reputación }\end{array}$} & $\begin{array}{l}\text { Aplicación de leyes y } \\
\text { regulaciones }\end{array}$ & Cumplimiento de la normativa \\
\hline & & $\begin{array}{l}\text { Mejora de la imagen o } \\
\text { reputación }\end{array}$ \\
\hline Para lograr financiamiento & $\begin{array}{l}\text { Mercados financieros } \\
\text { desarrollados }\end{array}$ & \\
\hline $\begin{array}{l}\text { Obtención de beneficios con el } \\
\text { gobierno }\end{array}$ & $\begin{array}{l}\text { Utilizar subsidios / incentivos } \\
\text { públicos existentes }\end{array}$ & \\
\hline $\begin{array}{l}\text { Encuazar al negocio con el } \\
\text { medio ambiente y lo social }\end{array}$ & $\begin{array}{c}\text { Aliados y organizaciones que } \\
\text { presentan sus ideas para } \\
\text { implementa en la empresa }\end{array}$ & \\
\hline Mejorar la utilidad & Mejora de la rentabilidad & \\
\hline
\end{tabular}

Fuente: Elaboración propia a partir de Madueño, J. H., Jorge, M. L., \& Sancho, M. P. L. (2014), Vives, A. (2008), Vives, A., Corral, A., \& Isusi, I. (2005), Vives, A. (2011), Aguilar, A. (2013), Madueno, J. H., Jorge, M. L., Sancho, M. P. L., \& Martínez-Martínez, D. (2015). 
A partir de este análisis se eligieron los siguientes impulsores que coincidieron en los seis estudios:

- Presiones de proveedores

- Altruismo

- Imagen pública
- Aumentar la rentabilidad de la empresa

- Valores personales y creencias éticas

Estos impulsores sirvieron como base para plantear una pregunta a las pymes restauranteras participantes de este estudio: En orden de importancia, ¿Cuál es el principal impulsor para que su empresa realice PRS? Sus respuestas se muestran a continuación:

Figura 1.

Principal impulsor de las PRS.

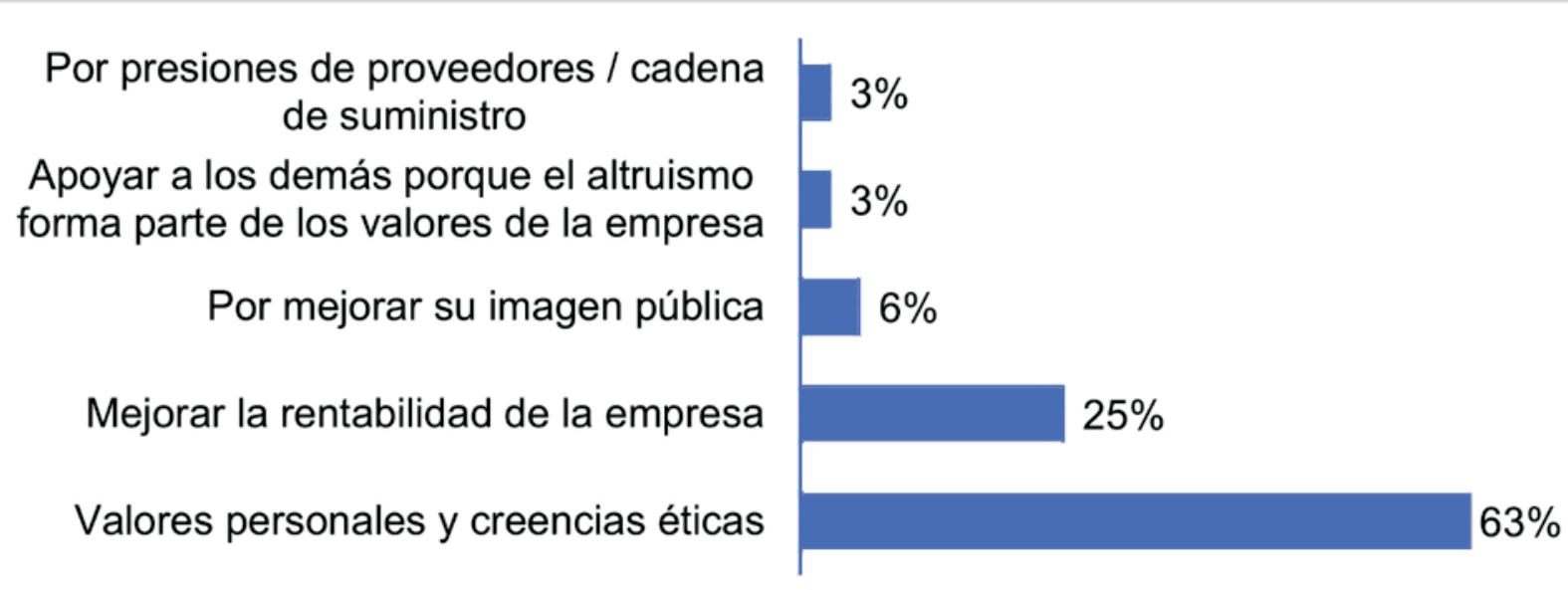

Fuente: Elaboración propia

Como se puede apreciar en la figura 1, el principal impulsor de las PRS es "los valores personales y creencias éticas" (63\%), seguida de "mejorar la rentabilidad de la empresa" (25\%). Con estos resultados se puede afirmar que el principal impulsor de las prácticas son los valores personales y las creencias éticas de quien esté al frente de la pyme, ya que la manera de conceptualizar, interpretar y realizar la RSE está relacionada con la forma en la que estos actores viven sus realidades, de esta forma impulsan la implementación de PRS a través de una estrategia que contribuya a satisfacer las necesidades y requerimientos de sus grupos de interés.

En definitiva, esto ofrece un escenario positivo para la implementación de la RSE en las pymes, ya que si bien existen empresarios cuyo principal motor para hacer PRS es de índole económico y político, hay también aquellos que buscan generar cambios importantes orientados hacia el bien común. No se debe olvidar que la RSE representa una nueva forma de gestionar las organizaciones para buscar el equilibrio entre el desarrollo económico, ambiental y social; y busca además crear PRS que ayuden a lograr una mejor interacción y entendimiento entre lo económico y lo ético para el bienestar común. Desde esta perspectiva, el encargado de la empresa tiene la responsabilidad de llevar a cabo esta tarea, pero ¿Qué cualidades y competencias debe tener para enfrentar tal reto?

De acuerdo con Abenoza y Lozano (2014), quien tiene la encomienda de implementar la RSE dentro de cualquier empresa debe ser una persona visionaria, versátil, con la capacidad de situarse en ambas partes para que a través del diálogo con sus grupos de interés, entienda su postura y escuche sus expectativas; debe estar convencida de la importancia de la RSE y de los beneficios que produce a largo plazo, así como también ser capaz de solucionar los problemas de la empresa de una manera creativa e innovadora. En este mismo sentido, estos autores afirman que:

El responsable de RSE tiene que ser alguien capaz de establecer complicidades. Si la RSE es transversal, su director debe ser alguien que no busque el protagonismo, sino que sea capaz de darlo a cada una de las áreas con las que trabaja, haciéndoles ver las ventajas que pueden aportar la transparencia y la sostenibilidad a su sector, empezando por el CEO. (Abenoza y Lozano, 2014, p.52) 
Asimismo, debe ser apto para elaborar estrategias donde participen los colaboradores, por lo que requiere ser un emprendedor disruptivo y arriesgado que esté dispuesto a nadar contracorriente, firme y a la vez empático y sensible. Más aún, debe tener un conocimiento profundo de la empresa de tal forma que sus propuestas sean bien recibidas por sus colaboradores quienes reconocen su profesionalismo que genera confianza, característica esencial de un director ético. También debe ser humilde para aceptar otros puntos de vista y reconocer que en ocasiones es probable perder el control, lo cual muestra que no es infalible y que está abierto a nuevas ideas. Una característica fundamental en estas personas es su humanidad, que sin duda le permite reconocer a las personas como el punto de partida y centro de todas sus decisiones. La apuesta, por tanto, está en la concientización al empresario, director, gerente o quién esté a cargo de una empresa. La pregunta es ¿cómo hacerlo?

Una de las tantas respuestas que se pueden ofrecer es considerar al estudio de la ética y la responsabilidad social como asignatura fundamental en los planes de estudio de carreras asociadas a administración de empresas y negocios, cursadas por quienes en un futuro estarán a cargo de alguna organización. Trabajar con estudiantes de estas carreras a través de esta manera implicaría estar en una constante reflexión que los lleve a identificar a quienes afectan con sus decisiones y con su trabajo, cuál es la intención y qué implicaciones tienen las decisiones que toman. Este ejercicio constante de discernimiento generaría un círculo virtuoso que contribuiría a forjar el carácter de los futuros directivos en ese sentido.

De esta manera, se afirma que implementar estrategias para incorporar las PRS en las empresas requiere de nuevas formas de gerencia; una que motive, que favorezca un clima armonioso, que propicie que los colaboradores sientan la confianza de comunicar sus iniciativas mostrando como resultado su compromiso con los procesos, que se sientan identificados porque son tomados en cuenta y, además, que se favorezca la promoción de liderazgos internos en donde se encuentren más espacios de realización personal.

Ahora bien, estudios como los de Herrera et al. (2014), muestran elementos que pueden ser considerados al momento de seleccionar quién debe estar a cargo de estas responsabilidades, pues se vuelven factores influyentes en la adopción e implementación de PRS:

a) Las pymes que cuentan con un propietario o gerente mujer perciben mayores motivaciones para realizar PRS que quienes son gerenciadas por hombres. b) Las pymes que cuentan con un propietario gerente con formación universitaria tienen más probabilidades de implementar de una manera más fácil y sin obstáculos las PRS que una pyme que esté gerenciada por una persona sin estudios universitarios.

En definitiva, lo más relevante es la formación de un pensamiento ético y de responsabilidad social en futuros directores, propietarios y empresarios, lo que implica desarrollar procesos de formación profesional que tengan una vinculación con su realidad social para que de esta forma el estudiante reflexione, se cuestione, analice y ponga en práctica estrategias que contribuyan a la búsqueda de soluciones a diferentes problemáticas sociales desde la implementación de PRS. Esto exige que las instituciones de educación superior que imparten carreras asociadas a administración de empresas o negocios fortalezcan sus ofertas formativas en este sentido.

Por otrolado, este trabajo presentado tienelimitaciones como el hecho de que se contemplaron empresas de Puebla que pertenecen al sector restaurantero, además de ser pymes, lo que significa que se excluyen a las microempresas y a las grandes corporaciones. Por lo que la muestra es bastante específica a esta realidad, lo que significa que, si el estudio se realiza a empresas con otras características, puede mostrar resultados diferentes o pueden confirmar que los valores personales y la conciencia ética del propietario, gerente o directivo, son el principal impulsor de las PRS, sea la empresa que sea.

Futuras investigaciones se puedan desarrollar en distintos contextos y con diferentes tamaños de empresas con la finalidad de hacer comparaciones y contrastar los diferentes factores mencionados. Esto también abonaría a investigar si existen otros factores que, a raíz de la situación mundial actual, son relevantes para la implementación de PRS como puede ser el rubro de la empresa, la edad de la empresa, su liquidez o su filosofía.

Por último, el presente artículo tuvo el objetivo de mostrar, además de los principales impulsores de las PRS en un tipo específico de empresa, la importancia de la persona dentro de la empresa que estará como responsable de desarrollar esta encomienda de implementación de las PRS, ya que de este perfil depende la relevancia que le dará a la Responsabilidad Social Empresarial como parte prioritaria de su empresa. 


\section{Referencia}

Abenoza, S., \& Lozano, J. (2014). La RSE ante el espejo. Entre el desencanto, la conciencia de oportunidad y el sentimiento de urgencia. Universidad Ramón Llull

Herrera Madueño, J., Larrán Jorge, M., Lechuga Sancho, M. P., \& Martínez-Martínez, D. (2014). Motivaciones hacia la Responsabilidad Social en las PYMEs familiares. European Journal of Family Business, 4(1), 21-44. https://doi.org/10.24310/ejfbejfb.v4i1.5037

Instituto Nacional de Estadística y Geografía (2020, 2 de diciembre). El INEGI presenta resultados de la segunda edición del ECOVID-IE y del estudio sobre la demografía de los negocios 2020 [Comunicado de prensa]. https://www.inegi.org.mx/contenidos/saladeprensa/boletines/2020/OtrTemEcon/ECOVID-IE_DEMOGNEG.pdf

Jamali, D., Zanhour, M. \& Keshishian, T. (2009). Peculiar Strengths and Relational Attributes of SMEs in the Context of CSR. Journal of Business Ethics, 87 (3), 355-377. 10.1007/s10551-008-9925-7

Villavicencio, J. M., Sánchez, R. B., Fornachiari, X. A., \& Solano, W. J. (2015). Factores que inciden en el desarrollo de la responsabilidad social empresarial: estudio realizado en el sector hotelero de San Carlos, Costa Rica. Tec Empresarial, 9(3), 7-18. https://doi.org/10.18845/te.v9i3.2431

Vives, A. (2008). El papel de la RSE en América Latina: ¿diferente al de Europa? Documentos de Trabajo (Fundación Carolina), (21)6, 63-77 file:///D:/Descargas/Dialnet-EIPapelDeLaRSEEnAmericaLatina-2573663.pdf 